\title{
Neuroendocrine prediction of left ventricular function and heart failure after acute myocardial infarction
}

A M Richards, M G Nicholls, T G Yandle, H Ikram, E A Espiner, J G Turner, R C Buttimore, J G Lainchbury, J M Elliott, C Frampton, I G Crozier, D W Smyth (The Christchurch Cardioendocrine Research Group)

\begin{abstract}
Objective-To determine the relations of plasma levels of brain natriuretic peptide (BNP), atrial natriuretic factor (ANF), N-terminal ANF (N-ANF), cyclic guanosine monophosphate (cGMP; the cardiac peptide second messenger), and plasma catecholamines to left ventricular function and to prognosis in patients admitted with acute myocardial infarction.

Design-Plasma hormones and ventricular function (radionuclide ventriculography) were measured 1-4 days after myocardial infarction in 220 patients admitted to a single coronary care unit. Radionuclide scanning was repeated 3-5 months after infarction. Clinical events were recorded over a mean period of 14 months.
\end{abstract}

Results-Both early and late left ventricular ejection fraction (LVEF) were most closely related to plasma BNP $(r=-0.60$, $\mathrm{n}=220, \mathrm{p}<0.001$; and $r=-0.53, \mathrm{n}=192$, p $<0.001$, respectively), followed by ANF, N-ANF, cGMP, and the plasma catecholamines. Early plasma BNP concentrations less than twofold the upper limit of normal (20 pmol/1) had $100 \%$ negative predictive value for $\mathrm{LVEF}<40 \%$ at $3-5$ months after infarction. In multivariate analysis incorporating all the neurohormonal factors, only BNP remained independently predictive of LVEF $<40 \%$ $(p<0.005)$. Survival analysis by median levels of candidate predictors identified BNP as the most powerful discriminator for death $(p<0.0001)$. No early deaths (within 4 months) occurred in patients with plasma BNP concentrations below the group median ( $27 \mathrm{pmol} / \mathrm{l})$, and over follow up only three of 26 deaths occurred in this subgroup. Of all episodes of left ventricular failure, $85 \%$ occurred in patients with plasma BNP above the median $(p<0.001)$. In multivariate analyses, BNP alone gave additional predictive information beyond sex, age, clinical history, LVEF, and plasma noradrenaline for both subsequent onset of LVF and death.

Conclusions-Plasma BNP measured within 1-4 days of acute myocardial infarction is a powerful independent predictor of left ventricular function, heart failure, or death over the subsequent 14 months, and superior to ANF, N-ANF, cGMP, and plasma catecholamines.

(Heart 1999;81:114-120)
Keywords: cardiac natriuretic peptides; noradrenaline; myocardial infarction; heart failure

Various circulating factors reflect left ventricular function and predict cardiovascular prognosis in a spectrum of cardiovascular disease ranging from severe heart failure of varied aetiology to well defined asymptomatic ischaemic left ventricular impairment. ${ }^{1-14}$ In recent reports the cardiac peptides have received particularly close attention as cardiovascular markers..$^{5-11}$ 13-17 However, which of atrial natriuretic factor (ANF), N-terminal ANF $(\mathrm{N}-\mathrm{ANF})$, or brain natriuretic peptide (BNP) is the most useful, whether plasma concentrations of the cardiac peptide second messenger cyclic guanosine monophosphate (cGMP) are as useful, and whether the cardiac peptides (or cGMP) are superior to other neurohumoral factors or add information beyond clinical indicators and left ventricular imaging remain unexplored or disputed. ${ }^{10-13} 1617$

To test the hypothesis that BNP, which is a ventricular product released in response to chamber wall stress, would prove superior to other markers, a prospective study was conducted to provide the first report of concurrent measurements and comparisons of plasma BNP, ANF, N-ANF, c-GMP, noradrenaline, and adrenaline in detecting left ventricular dysfunction (assessed by radionuclide ventriculography) and predicting clinical events after myocardial infarction.

\section{Methods}

We studied 220 patients (table 1) admitted to the Christchurch Hospital coronary care unit with acute myocardial infarction between November 1994 and December 1995. Acute myocardial infarction was defined by the presence of typical cardiac ischaemic symptoms, ischaemic change on the ECG in two or more contiguous leads, and peak elevation of plasma creatine kinase to at least twice normal (400 $\mathrm{U} / 1)$. Inclusion criteria included age less than 80 years, absence of cardiogenic shock, and survival for at least 24 hours after myocardial infarction.

Blood samples were taken 24 to 96 hours after the onset of symptoms, in the morning (07:00-13:00), from an indwelling intravenous cannula placed at least 30 minutes before sampling and with the patient resting quietly while semirecumbent. Samples were taken into chilled EDTA vacutainers, placed immediately on ice, centrifuged within 20 minutes at $4^{\circ} \mathrm{C}$,
Accepted for publication 14 September 1998 
Table 1 Clinical, neurohormonal, and left ventricular scan data from 220 acute myocardial infarction patients

\begin{tabular}{|c|c|}
\hline \multicolumn{2}{|l|}{ Clinical variables } \\
\hline Age (years) & $63(10)$ \\
\hline Male sex (\%) & 78 \\
\hline Body mass index $\left(\mathrm{kg} / \mathrm{m}^{2}\right)$ & $27.0(4.6)$ \\
\hline \multicolumn{2}{|l|}{ Position of infarct (\%) } \\
\hline Anterior & 39 \\
\hline Inferior & 51 \\
\hline Other & 10 \\
\hline Peak creatine kinase $(\mathrm{U} / 1)(<150)^{\star}$ & $1971(1506)$ \\
\hline Peak troponin $\mathrm{T}(\mathrm{U} / \mathrm{l})(<0.01)^{\star}$ & $13(8)$ \\
\hline Total cholesterol (mmol/l) & $6.13(1.3)$ \\
\hline \multicolumn{2}{|l|}{ Previous history $(\%)$} \\
\hline Angina & 45 \\
\hline Myocardial infarction & 24 \\
\hline Cerebrovascular disease & 11 \\
\hline Peripheral vascular disease & 10 \\
\hline Diabetes mellitus & 14 \\
\hline Hypertension & 39 \\
\hline Smoker, current & 26 \\
\hline Smoker, past & 36 \\
\hline \multicolumn{2}{|l|}{ Hormone and scan data } \\
\hline Brain natriuretic peptide $(\mathrm{pmol} / \mathrm{l})$ & $32(21)$ \\
\hline Atrial natriuretic factor $(\mathrm{pmol} / \mathrm{l})$ & $38(32)$ \\
\hline $\mathrm{N}$-terminal atrial natriuretic factor $(\mathrm{pmol} / \mathrm{l})$ & 2299 (1776) \\
\hline Cyclic guanosine monophosphate $(\mathrm{nmol} / \mathrm{l})$ & $6.3(3.3)$ \\
\hline Noradrenaline $(\mathrm{nmol} / \mathrm{l})^{2}$ & $2.22(1.40)$ \\
\hline Adrenaline (pmol/1) & $210(184)$ \\
\hline Left ventricular ejection fraction (\%) & $46(13)$ \\
\hline Left ventricular end diastolic volume ( $\mathrm{ml})$ & $154(53)$ \\
\hline Left ventricular end systolic volume (ml) & $87(47)$ \\
\hline
\end{tabular}

and the plasma stored at $-80^{\circ} \mathrm{C}$ before assay. Cardiac peptides were measured by our locally developed radioimmunoassays, ${ }^{18} 19$ cGMP by the method of Steiner et $a l_{,}^{20}$ and catecholamines by high performance liquid chromatography with electrochemical detection. ${ }^{21}$ Intraassay and interassay coefficients of variation were within $8 \%$ and $9 \%$, respectively, for all assays.

Left ventricular function was assessed by radionuclide ventriculography within 24 hours of blood sampling. Each study was performed using a General Electric 400AC gamma camera interfaced to a General Electric 3000i computer system (General Electric Medical Systems, Milwaukee, Wisconsin, USA) following standard in vivo technetium-99m red blood cell labelling. Patients underwent repeat radionuclide scanning at three to five months after infarction.

Clinical events including death, acute ischaemic coronary syndromes, and heart failure (defined by presence of new symptoms of dyspnoea and/or oedema, with one or more concordant signs including ventricular gallop rhythm, pulmonary crepitations, raised venous pressure, and radiological evidence of left ventricular failure) were recorded over a mean follow up period of 14 months.

\section{STATISTICAL ANALYSIS}

Values are expressed as mean (SD). The Pearson product moment correlation coefficient was used to measure linear correlations between variables. For correlation analysis the log of neurohumoral factors was used to normalise the distribution of data. Correlations were compared using a $\mathrm{z}$ test on normally transformed correlation coefficients.

The relative abilities of neurohumoral factors to predict left ventricular ejection fraction $(\mathrm{LVEF})<40 \%$, or new onset heart failure dur- ing follow up were assessed by receiver operating characteristic (ROC) analysis. Areas under the ROC curves for each marker were compared using the method of Hanley and McNeil. ${ }^{22}$ Optimal values for specificity and sensitivity were estimated by finding the position on the ROC curves with the minimum Euclidean distance to the point of perfect specificity and sensitivity $(100 \%, 100 \%)$. Multiple logistic regression was undertaken to test for independent prediction of LVEF $<40 \%$ by one or more neurohumoral factors.

Mean levels of neurohumoral factors, ejection fraction, and ventricular volumes were compared using independent $t$ tests for patients experiencing or spared specific adverse events. Cumulative adverse event rates were compared using $\chi^{2}$ tests (with Yates' correction for low expected frequencies) and risk ratios (with $95 \%$ confidence intervals) calculated between patient groups with admission levels above and below the median of individual neurohumoral factors, ejection fraction, and left ventricular volumes. Kaplan-Meier survival curves were constructed for subgroups with neurohormonal and ventricular scan variables above and below the group medians.

Multivariate analyses were conducted including demographic and clinical variables (age, sex, history of previous myocardial infarction, hypertension, diabetes, and previous heart failure) as standard predictors forced into the model to test for any further independent predictive power provided by candidate indicators (including LVEF and plasma neurohormones) for three specific outcomes-left ventricular failure, death, and the combined end point of left ventricular failure and/or death. Concordant with $\chi^{2}$ analyses of event rates and Kaplan-Meier analyses, candidate markers were entered in the multiple logistic regression analyses as binary variables (above or below the median).

\section{Results}

Between November 1994 and December 1995, 451 patients with myocardial infarction were admitted to the coronary care unit. Four per cent died within 24 hours of onset of symptoms, $11 \%$ were excluded as peak creatine kinase did not exceed $400 \mathrm{U} / 1$, and a further $10 \%$ were aged over 80 years or suffered cardiogenic shock. Of the remaining 338 eligible patients, 220 consented to participate in the study. Clinical and demographic features of the group are given in table 1 . At discharge $96 \%$ of the group were receiving aspirin, $84 \% \beta$ blockers, $47 \%$ angiotensin converting enzyme (ACE) inhibitors, and $24 \%$ diuretics. Plasma neurohumoral results and left ventricular indices for the group are given in table 1. Mean plasma concentrations of both ANF and BNP were raised $(p<0.001)$ to well above the upper limit of normal (2 SD above mean of 168 age matched normal subjects $=25 \mathrm{pmol} / 1$ and 10 $\mathrm{pmol} / 1$ for $\mathrm{ANF}$ and BNP, respectively) and showed a broad dispersion. In contrast, mean noradrenaline and adrenaline concentrations were within the normal range $(<3.9 \mathrm{nmol} / 1$ and $<500 \mathrm{pmol} / 1$, respectively). Normal ranges 

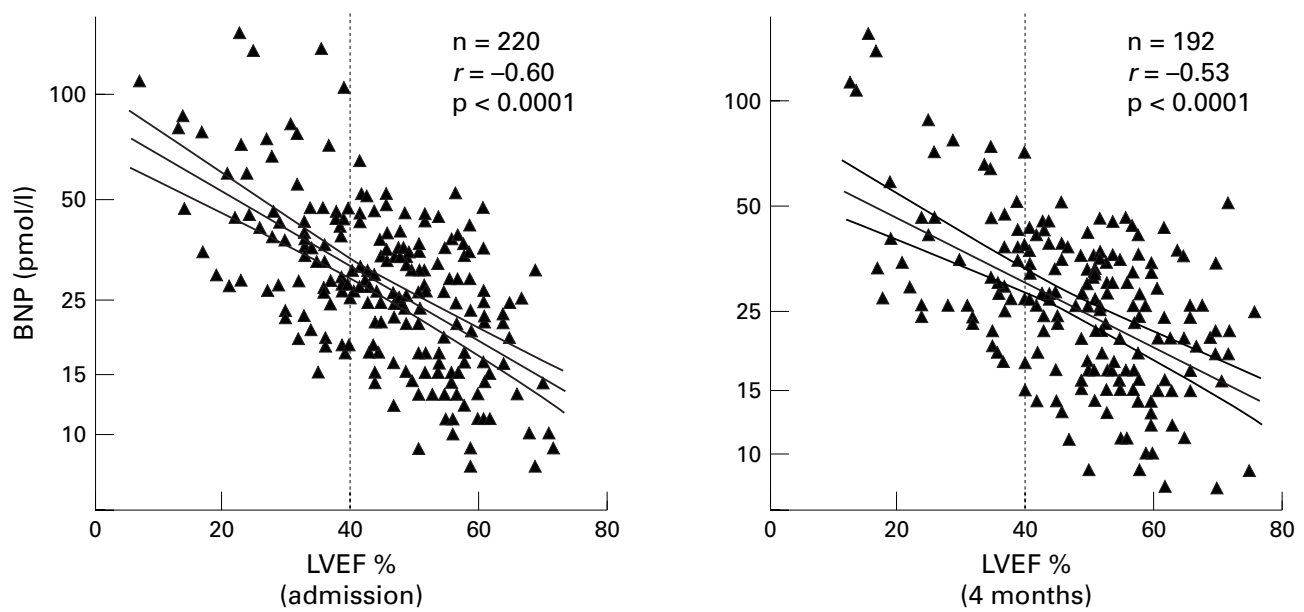

Figure 1 Individual early postinfarction plasma concentrations of brain natriuretic peptide (BNP; log scale) plotted against corresponding early (left; "admission") and late (right; "4 months") postinfarction radionuclide scan left ventricular ejection fraction (LVEF) (regression lines with 95\% confidence intervals) for 220 patients with myocardial infarction. Vertical dashed lines are marked at 40\% ejection fraction. BNP concentrations $<20$ pmol/l (that is, less than twice the upper limit of normal) correspond to a late ejection fraction greater than $40 \%$.

for plasma cGMP and N-ANF have yet to be formally established but the concentrations were significantly higher than measured in 35 normal subjects (not age matched).

Strong positive relations were observed between early plasma $\mathrm{ANF}$ and concurrent levels of BNP, cGMP, and N-ANF $(r=0.74$, 0.69 , and 0.60 , respectively; $\mathrm{n}=220$; all $\mathrm{p}<0.001)$ but associations of any cardiac peptide (or cGMP) with noradrenaline were weaker $(r=0.07-0.31 ; \mathrm{p}=\mathrm{NS}-<0.001)$.

\section{HORMONES AND LEFT VENTRICULAR EJECTION} FRACTION

Inverse relations between LVEF and concomitant cardiac peptide concentrations were strongest for BNP $(r=-0.60, \mathrm{n}=220$, $\mathrm{p}<0.0001)$ and weaker for ANF $(-0.47$; $\mathrm{p}<0.001), \mathrm{N}-\mathrm{ANF}(-0.31 ; \mathrm{p}<0.001)$, and cGMP $(-0.42 ; \mathrm{p}<0.001)$. Relations of LVEF with noradrenaline and adrenaline $(r=-0.26$ and -0.17), though statistically significant $(\mathrm{p}<0.001$ and $\mathrm{p}<0.05$ respectively), were weak. The association between BNP and LVEF was significantly stronger than for any other marker $(p<0.05-0.001)$ except ANF $(p=0.063)$. The slope and strength of the relations between BNP and LVEF were similar whether BNP values were plotted against early or late LVEF measurements (fig 1).

ROC analyses of the sensitivity and specificity of neurohormonal markers to detect an LVEF value of $<40 \%$ (table 2 ) showed that the optimum level of plasma BNP ( $\geqslant 25 \mathrm{pmol} / \mathrm{l}$ ) had greater sensitivity $(81 \%)$ than any other marker, and comparison of ROC curves indicated a statistically significant advantage for BNP over noradrenaline and adrenaline $(\mathrm{p}<0.05$ for both). Multiple logistic regression analysis suggested that $\mathrm{BNP}$ alone predicted an LVEF of $<40 \%$ independently of all the other neurohumoral factors measured $(p<0.005)$. Plasma BNP concentrations below $20 \mathrm{pmol} / 1$ measured one to four days postinfarction gave $100 \%$ predictive power that LVEF measured three to five months later would be not less than $40 \%$ (fig 1 ). In contrast, the positive predictive power of all hormones was modest (only $32-47 \%$ for LVEF $<40 \%$ ). BNP concentrations between 25 and $60 \mathrm{pmol} / 1$ corresponded to LVEF values over a wide range (20-70\%; fig 1). Only in the small group of patients with early postinfarct BNP concentrations over $60 \mathrm{pmol} / \mathrm{l}(\mathrm{n}=15 / 220)$ was there

Table 2 Sensitivity, specificity, and predictive power of optimal levels of markers for left ventricular ejection fraction $(L V E F)<40 \%$ and for subsequent development of left ventricular failure (LVF)

\begin{tabular}{|c|c|c|c|c|c|}
\hline & Optimum level & Sensitivity (\%) & Specificity (\%) & $P P V(\%)$ & $N P V(\%)$ \\
\hline \multicolumn{6}{|l|}{$L V E F<40 \%$} \\
\hline $\mathrm{BNP}(\mathrm{pmol} / \mathrm{l})$ & $\geqslant 25$ & 81 & 56 & 48 & 85 \\
\hline $\mathrm{ANF}(\mathrm{pmol} / \mathrm{l})$ & $\geqslant 33$ & 64 & 63 & 47 & 77 \\
\hline N-ANF (pmol/1) & $\geqslant 1620$ & 66 & 43 & 37 & 71 \\
\hline $\mathrm{cGMP}(\mathrm{nmol} / \mathrm{l})$ & $\geqslant 5.89$ & 65 & 62 & 47 & 78 \\
\hline Noradrenaline $(\mathrm{nmol} / \mathrm{l})$ & $\geqslant 1.81$ & 63 & 55 & 42 & 74 \\
\hline Adrenaline $(\mathrm{pmol} / \mathrm{l})$ & $\geqslant 144$ & 71 & 50 & 32 & 65 \\
\hline \multicolumn{6}{|l|}{$L V F$} \\
\hline $\mathrm{BNP}(\mathrm{pmol} / \mathrm{l})$ & $\geqslant 33$ & 84 & 77 & 47 & 95 \\
\hline $\mathrm{ANF}(\mathrm{pmol} / \mathrm{l})$ & $\geqslant 37$ & 81 & 75 & 46 & 94 \\
\hline $\mathrm{N}-\mathrm{ANF}(\mathrm{pmol} / \mathrm{l})$ & $\geqslant 2200$ & 84 & 69 & 42 & 94 \\
\hline $\mathrm{cGMP}(\mathrm{nmol} / \mathrm{l})$ & $\geqslant 6.31$ & 72 & 70 & 39 & 90 \\
\hline Noradrenaline $(\mathrm{nmol} / \mathrm{l})$ & $\geqslant 1.85$ & 72 & 59 & 36 & 87 \\
\hline Adrenaline (pmol/l) & $\geqslant 156$ & 71 & 56 & 34 & 86 \\
\hline LVEF (\%) & $\leqslant 47$ & 79 & 58 & 33 & 91 \\
\hline
\end{tabular}

Highest values for each end point are given in bold type. Optimum levels of candidate indicators were selected from receiver operating characteristic curves (fig 3 ).

ANF, atrial natriuretic factor; BNP, brain natriuretic peptide; cGMP, cyclic guanosine monophosphate; LVEF, left ventricular ejection fraction; N-ANF, N-terminus ANF; NPV, negative predictive value; PPV, positive predictive value. 
Table 3 Plasma neurohormone concentrations and left ventricular indices measured one to four days after myocardial infarction in patients with and without subsequent adverse events over a mean 14 month follow up

\begin{tabular}{|c|c|c|c|c|c|c|c|c|c|c|}
\hline & $n$ & $\begin{array}{l}\text { BNP } \\
\text { (pmol/l) }\end{array}$ & $\begin{array}{l}A N F \\
(p m o l / l)\end{array}$ & $N-A N F(p m o l / l)$ & $\begin{array}{l}c G M P \\
(\text { nmolll) }\end{array}$ & $\begin{array}{l}\text { Adrenaline } \\
\text { (pmol/l) }\end{array}$ & $\begin{array}{l}\text { Noradrenaline } \\
(\text { nmol/l) }\end{array}$ & LVEF (\%) & LVEDV $(\mathrm{ml})$ & LVESV $(m l)$ \\
\hline \multicolumn{11}{|l|}{ Death } \\
\hline Yes & 26 & $52(35)^{\star \star \star}$ & $68(66)^{\star \star \star}$ & $4054(2333)^{\star \star \star}$ & $8.5(5.8)^{\star \star \star}$ & $210(112)$ & $2.84(1.79)^{\star}$ & $35(16)^{\star \star \star}$ & $203(86)^{\star \star \star}$ & $140(73)^{\star \star \star}$ \\
\hline No & 194 & $29(17)$ & $34(22)$ & $2064(1346)$ & $6.0(2.6)$ & $204(174)$ & $2.19(1.19)$ & $47(12)$ & $147(38)$ & $79(32)$ \\
\hline \multicolumn{11}{|c|}{ Heart failure } \\
\hline Yes & 56 & $50(30)^{\star \star \star}$ & $65(51)^{\star \star \star}$ & $3640(2113)^{\star \star \star}$ & $8.8(4.6)^{\star \star \star}$ & $256(160)^{\star}$ & $3.20(1.68)^{\star \star \star}$ & $36(15)^{\star \star \star}$ & $183(69)^{\star \star \star}$ & $122(59)^{\star \star \star}$ \\
\hline No & 164 & $25(12)$ & $29(14)$ & $1841(1074)$ & $5.5(2.0)$ & $188(169)$ & $1.95(0.96)$ & $49(10)$ & $144(35)$ & $75(27)$ \\
\hline \multicolumn{11}{|c|}{ Acute coronary syndrome } \\
\hline Yes & 66 & $34(23)$ & $40(41)$ & 2448 (1618) & $6.5(3.6)$ & $174(116)$ & $2.26(1.15)$ & $46(15)$ & $149(49)$ & $84(44)$ \\
\hline No & 154 & $31(20)$ & $37(28)$ & $2236(1848)$ & $6.3(3.2)$ & $218(194)$ & $2.27(1.39)$ & $46(13)$ & $156(55)$ & $88(48)$ \\
\hline
\end{tabular}

Values are mean $(\mathrm{SD})$

${ }^{\star} \mathrm{p}<0.05 ;{ }^{\star \star \star} \mathrm{p}<0.001$, comparison of those with and without event.

ANF, atrial natriuretic factor; BNP, brain natriuretic peptide; cGMP, cyclic guanosine monophosphate; LVEDV, left ventricular end diastolic volume; LVEF, left ventricular ejection fraction; LVESV, left ventricular end systolic volume; NA, noradrenaline; N-ANF, N-terminus ANF.

$100 \%$ positive predictive power for an LVEF of $<40 \%$ (fig 1).

HORMONES AND CLINICAL EVENTS

During follow up, 26 deaths (23 cardiovascular), 56 heart failure events, and 65 acute coronary syndrome events were recorded (cumulative event rates of $12 \%, 25 \%$, and $30 \%$, respectively). Early postinfarct values for $\mathrm{BNP}, \mathrm{ANF}, \mathrm{N}-\mathrm{ANF}$, cGMP, noradrenaline, and left ventricular volume were significantly higher and LVEF was significantly lower in patients who died or developed heart failure in the follow up period (table 3). Adrenaline concentrations were higher in those developing heart failure but not significantly so in patients who died. Neither neurohormones nor LVEF differed between those incurring or avoiding new acute coronary ischaemic syndromes.

ROC analysis indicated that early neurohumoral levels had generally better sensitivity and specificity for predicting the subsequent development of left ventricular failure than for indicating an LVEF value of $<40 \%$ (table 2 ). Optimal postinfarct values for BNP, ANF, and $\mathrm{N}-\mathrm{ANF}$ had sensitivities of $80-84 \%$ and specificities of $77 \%, 75 \%$, and $69 \%$, respectively, for prediction of left ventricular failure. Other markers had lesser specificity and sensitivity.

Median early BNP and ANF values in particular discriminated between patients destined or not to die or to develop heart failure (table 4). No patient with early postinfarct $\mathrm{BNP}$ concentrations below the group median died in the first four months after infarction (fig
2). Over $80 \%$ of those developing heart failure over follow up had early BNP or ANF concentrations above the group median. N-ANF and cGMP values and left ventricular scan indices had comparable though marginally weaker predictive power for heart failure, while noradrenaline and adrenaline were clearly much weaker (tables 2-4). Kaplan-Meier survival curves for subgroups divided according to median hormone values and left ventricular scan data (fig 2) showed significant separation of curves for BNP, N-ANF, ANF (fig 2), left ventricular end systolic volume, left ventricular end diastolic volume, and LVEF ( $p<0.001$ for all three left ventricular scan indices), but not for cGMP (fig 2), adrenaline $(p=0.91)$, or noradrenaline $(\mathrm{p}=0.76)$.

Multiple logistic regression indicated that both BNP $(p<0.05)$ and age $(p<0.05)$ were predictive of death independently of sex, clinical history, noradrenaline, and LVEF. BNP $(p<0.01)$, age $(p<0.05)$, a previous history of heart failure $(p<0.05)$, and LVEF $(\mathrm{p}<0.05)$ all gave independent information predictive of left ventricular failure. Similarly, for the composite end point of death and/or heart failure, BNP $(p<0.001)$, LVEF $(\mathrm{p}<0.05)$, and age $(\mathrm{p}<0.05)$ all gave independent information. When serial analyses were conducted substituting ANF, N-ANF, and then cGMP (in place of BNP), all three failed to give independent prediction of death though all achieved statistical significance for independent prediction of left ventricular failure or the composite end point of death and/or left ventricular failure.

Table 4 Risk ratios (95\% confidence intervals) for adverse events according to median levels of neurohormonal markers and left ventricular scan indices measured one to four days after myocardial infarction $(n=220)$

\begin{tabular}{|c|c|c|c|c|}
\hline & \multirow[b]{2}{*}{$\begin{array}{l}\text { Median } \\
\text { value }\end{array}$} & \multicolumn{3}{|c|}{ Relative risk ( $95 \%$ confidence interval) } \\
\hline & & Death $(n=26)$ & Heart failure $(n=56)$ & $\begin{array}{l}\text { Unstable coronary syndrome } \\
(n=65)\end{array}$ \\
\hline $\mathrm{BNP}(\mathrm{pmol} / \mathrm{l})$ & 27 & $6.0(2.1 \text { to } 16.9)^{\star \star \star}$ & $5.0(2.7 \text { to } 9.5)^{\star \star \star}$ & $1.4(1.0$ to 2.2$)$ \\
\hline $\mathrm{ANF}(\mathrm{pmol} / \mathrm{l})$ & 30 & $2.8(1.2 \text { to } 6.4)^{\star \star}$ & $5.4(2.8 \text { to } 10.5)^{\star \star \star}$ & $1.1(0.7$ to 1.6$)$ \\
\hline $\mathrm{N}-\mathrm{ANF}(\mathrm{pmol} / \mathrm{l})$ & 1865 & $4.2(1.6 \text { to } 10.7)^{\star \star \star}$ & $3.3(1.9 \text { to } 5.8)^{\star \star \star}$ & $1.2(0.8$ to 1.9$)$ \\
\hline $\mathrm{cGMP}(\mathrm{nmol} / \mathrm{l})$ & 5.7 & $1.3(0.6$ to 2.8$)$ & $3.3(1.9 \text { to } 5.8)^{\star \star \star}$ & $1.1(0.8$ to 1.7$)$ \\
\hline Noradrenaline $(\mathrm{nmol} / \mathrm{l})$ & 1.94 & $0.9(0.4$ to 1.8$)$ & $1.9(1.2 \text { to } 3.1)^{\star \star}$ & $1.1(0.7$ to 1.7$)$ \\
\hline Adrenaline $(\mathrm{pmol} / \mathrm{l})$ & 164 & $1.0(0.5$ to 2.1$)$ & $1.8(1.1 \text { to } 2.9)^{\star}$ & $0.8(0.5$ to 1.2$)$ \\
\hline LVEF $(\%)$ & 47 & $2.6(1.1 \text { to } 5.9)^{\star}$ & $3.4(1.9 \text { to } 6.1)^{\star \star \star}$ & $1.1(0.7$ to 1.7$)$ \\
\hline LVEDV (ml) & 145 & $2.6(1.1 \text { to } 5.9)^{\star}$ & $2.1(1.3 \text { to } 3.4)^{\star \star}$ & $0.9(0.6$ to 1.4$)$ \\
\hline LVESV (ml) & 77 & $3.5(1.4 \text { to } 8.3)^{\star \star}$ & $4.1(2.3 \text { to } 7.6)^{\star \star \star}$ & $1.0(0.7$ to 1.5$)$ \\
\hline
\end{tabular}

${ }^{\star} \mathrm{p}<0.05 ;{ }^{\star \star} \mathrm{p}<0.01 ;{ }^{\star \star \star} \mathrm{p}<0.001\left(\chi^{2}\right.$ analysis $)$.

For neurohormonal markers and left ventricular volumes, risk ratios were calculated from event rates above divided by rates below group medians, and for LVEF below/above the median.

ANF, atrial natriuretic factor; BNP, brain natriuretic peptide; cGMP, cyclic guanosine monophosphate; LVEDV, left ventricular end diastolic volume; LVEF, left ventricular ejection fraction; LVESV, left ventricular end systolic volume; N-ANF, N-terminus ANF. 

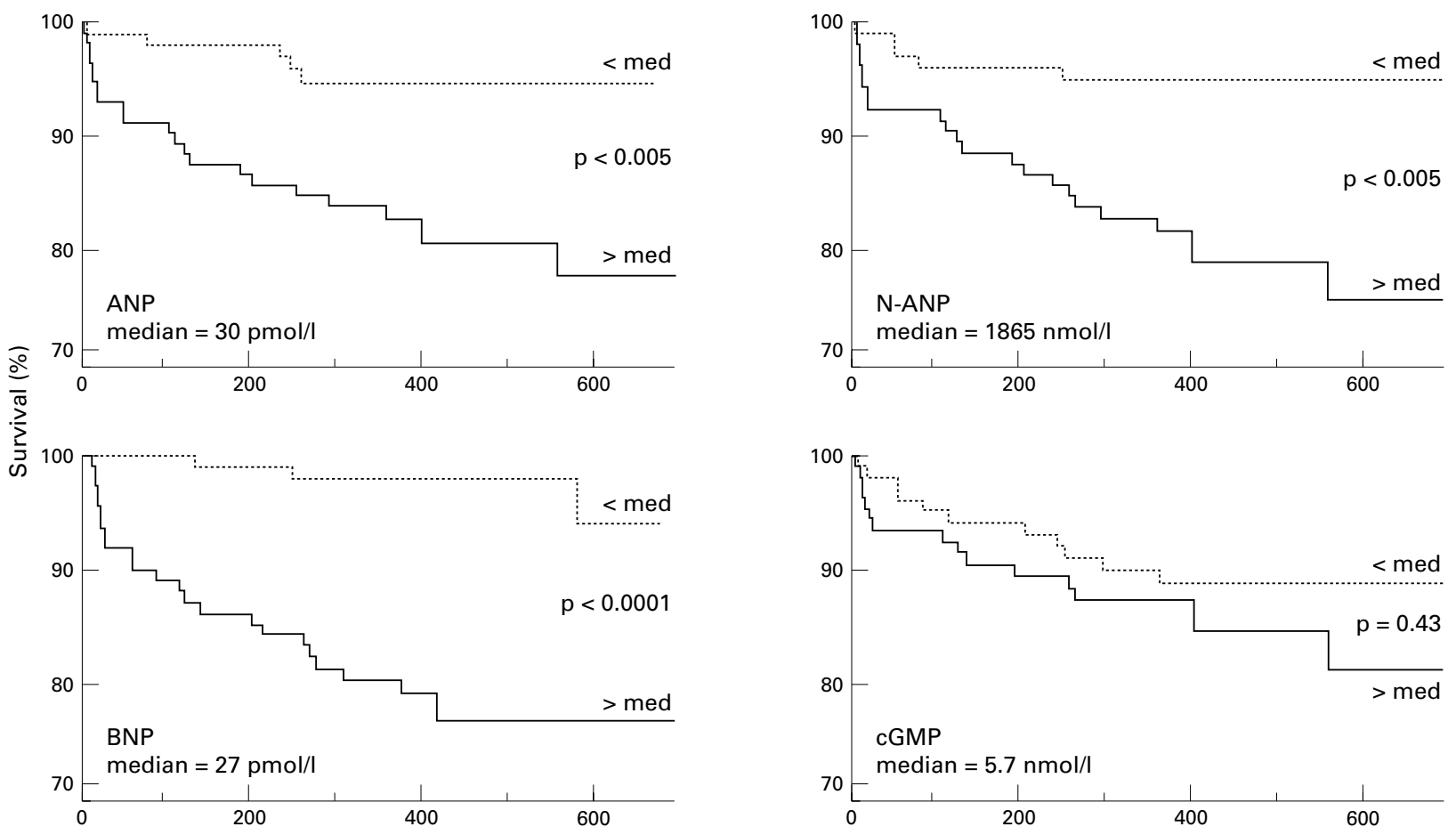

Time (days)

Figure 2 Kaplan-Meier survival curves for subgroups with early postinfarction plasma peptides (ANF, N-ANF, BNP) and cGMP concentrations above (solid line) and below (dashed line) the group median in 220 patients with myocardial infarction. ANF, atrial natriuretic factor; BNP, brain natriuretic peptide; cGMP, cyclic guanosine monophosphate; $N$-ANF, $N$-terminal ANF.

\section{Discussion}

Recent reports indicate that neurohormonal measurements reflect left ventricular function and add useful information beyond clinical features and cardiac imaging procedures in predicting outcomes after myocardial infarction, and in both staging and prognosis for patients with established congestive heart failure. $^{23} 24$ However, there is conflict and inconsistency in existing reports. ${ }^{2}{ }^{10-13}$

Our study provides the first prospective single centre comparison of the value of multiple neurohumoral measurements in assessing left ventricular function and prognosis in a typical and substantial population of patients suffering myocardial infarction and passing through a single coronary care unit within little over a year. The study design also allowed us to examine the relative ability of early measurements of an array of neurohormonal variables to predict left ventricular function several months after infarction. It is also the first report to extend the investigation of an array of neurohormonal variables to their potential predictive power for morbid postinfarction end points (heart failure and ischaemic syndromes) as well as mortality. Whereas in many previous studies subjects have been preselected according to left ventricular function or symptomatic status, ${ }^{27121525}$ in our investigation we tested the applicability of neurohormonal measurements in a substantial population embracing a wide spectrum of pre-existing morbidity, age, and severity of infarction as typifies current coronary care practice in the thrombolytic era. The protocol was practical, requiring a single sample for blood hormone levels and initial radionuclide scanning within a 24 to 96 hour window following the onset of infarction.

HORMONES AND LEFT VENTRICULAR EJECTION FRACTION

The plasma concentrations of the cardiac peptides, and BNP in particular, were strongly related to left ventricular ejection fraction measured both early (one to four days) and late (three to five months) after infarction. These results concur with those reported by Davidson et al, Yamamoto et al, and Motwani et al, ${ }^{10} 1117$ and contrast with those of Omland et $a l,{ }^{13}$ in showing that the inverse correlation of BNP and LVEF is stronger than those for ANF or $\mathrm{N}$-ANF. This relation has practical value in that a plasma BNP of less than twice the upper limit of normal within days of myocardial infarction carried $100 \%$ predictive power that late LVEF would not fall below $40 \%$. However, the positive predictive power of these hormone levels for impaired left ventricular function is limited. In contrast to data from Motwani et $a l,{ }^{17} \mathrm{BNP}$ levels from 20 to $60 \mathrm{pmol} / 1$ were associated with a broad range of LVEF values, from normal to severely reduced $(20 \%$ to $70 \%)$.

HORMONES AND CLINICAL EVENTS

BNP had the highest sensitivity, specificity, positive predictive value, and negative predictive value (table 2 ) for heart failure during follow up. Multivariate analyses indicated that any one of BNP, ANF, N-ANF, or cGMP added additional information beyond clinical features, noradrenaline concentrations, and LVEF in predicting heart failure or the composite end point of death and/or heart failure. Among the 
cardiac peptides, $\mathrm{BNP}$ and $\mathrm{ANF}$ were the most powerful in this regard, with nothing to be gained from measuring more than one of these, or N-ANF or cGMP. LVEF also provided independent information.

BNP was also the strongest single hormonal predictor of death by several univariate analyses (tables 3 and 4; fig 1). Multivariate analyses also indicated that BNP alone among the hormones tested was independently predictive of death. For left ventricular failure or the composite end point of death and/or left ventricular failure, any one of $\mathrm{ANF}, \mathrm{N}-\mathrm{ANF}$, cGMP, and BNP provided independent predictive information (as did age and LVEF). $\mathrm{BNP}$ has previously been reported to predict mortality in some categories of cardiac injury. ${ }^{13} 141617$ In contrast to smaller series in which BNP has been reported to correlate less well with LVEF but better with mortality ${ }^{13}$ or better with mortality but less well with heart failure ${ }^{17}$ than ANF, our larger study shows that $\mathrm{BNP}$ is consistently more closely related to left ventricular dysfunction and mortality than the other neurohormones measured, while retaining an association with left ventricular failure comparable to that seen with the other cardiac peptides and with left ventricular scan data.

Although mean noradrenaline concentrations were increased in those dying or developing left ventricular failure during follow up, in multivariate analysis noradrenaline did not provide independent information. Generally, our findings are in accord with reports that have shown the superiority of ANF over noradrenaline as a cardiovascular marker ${ }^{5} 1525$ in the postinfarction setting, and our data extend this conclusion to BNP, N-ANF, and cGMP.

Although plasma cGMP maintained obvious relations with concomitant plasma cardiac peptides (most notably ANF), it was clearly a less powerful indicator of LVEF or of death than BNP. This is presumably because plasma cGMP concentrations merely reflect spillover into the circulation of a tiny proportion of the cGMP produced intracellularly. Changes in cGMP also occur in response to various other stimuli including nitric oxide, as well as cardiac peptide levels. However, it performed as well as $\mathrm{N}$-ANF and better than noradrenaline in the prediction of heart failure.

It has previously been reported that N-ANF predicts prognosis and left ventricular function. ${ }^{6-10}$ In the current study, N-ANF was consistently and significantly related to the other cardiac peptides and to cGMP as well as to LVEF and to adverse outcomes. Notably $\mathrm{N}$-ANF had a high sensitivity for predicting heart failure (table 2). However, it clearly performed less well than BNP (or ANF) as a predictor of death or as an indicator of LVEF. The latter seems intuitively acceptable as BNP is released from the ventricle (the only truly "ventricular" hormone measured in the study) in response to left ventricular wall stress and might logically be most closely related to the state of the left ventricle. The finding conflicts with other studies ${ }^{10}{ }^{13}$ reporting that N-ANF is equal or superior to $\mathrm{BNP}$ in predicting an
LVEF $\leqslant 45 \%$ in smaller groups with left ventricular impairment of mixed aetiology. ${ }^{10}$ The current study indicates that within days or months of myocardial infarction, N-ANF will be less closely related to left ventricular size and function than BNP.

Non-fatal acute coronary syndromes were not predicted by any of the candidate markers measured, perhaps reflecting the weakness of any relation between intracardiac pressures (the prime regulator of cardiac peptide release) and vulnerability to coronary atherosclerotic plaque rupture.

\section{LIMITATIONS}

A shortcoming of our study, and all similar studies, is the necessary limit to the number of potential neurohumoral markers assessed. Renin was not measured because many of the group received converting enzyme inhibitors, thus distorting any relation between renin and ventricular function or cardiovascular prognosis. Endothelin has shown promise despite its diffuse vascular (rather than specific cardiac) origin, and warrants further study. ${ }^{26-28}$ Similarly, further consideration of cytokines including tumour necrosis factor is also required. ${ }^{29}{ }^{30}$ The list of circulating factors with potential prognostic value will inevitably expand with time.

\section{CONCLUSIONS}

Among plasma cardiac peptides, cGMP, and the catecholamines, the ventricular hormone BNP best reflects left ventricular function and gives independent prognostic information on the risk of death or heart failure in the months following myocardial infarction. Stratification of patients into low and high risk groups can be greatly facilitated by plasma BNP measurements and these could reasonably be included in the routine clinical work up of patients following myocardial infarction.

We gratefully acknowledge the assistance of Ms Leanne Liggett and Mrs Rose Richards (research assistants), nuclear medicine and endocrine department technical and nursing staff, and coronary care nursing staff. Funding was provided by grants from the National Heart Foundation of New Zealand and the Health Research Council of New Zealand. Secretarial assistance was Research Council of New Zealand. Secretarial assistance was Foundation (NZ) Chair of Cardiovascular Studies.

1 Cohn JN, Levine TB, Olivari MT, et al. Plasma norepinephrine as a guide to prognosis in patients with chronic congestive heart failure. $N$ Engl f Med 1984;311:819-23.

2 Francis GS, Benedict C, Johnstone DE, et al. Comparison of neuroendocrine activation in patients with left ventricular dysfunction with and without congestive heart failure. A substudy of the studies of left ventricular dysfunction substudy of the studies of left vent

3 Svanegaard J, Angelo-Nielsen K, Pindborg T. Plasma concentration of atrial natriuretic peptide at admission and risk of cardiac death in patients with
arction. Br Heart $\mathcal{F} 1992 ; 68: 38-42$.

4 Davis KM, Fish LC, Elahi D, et al. Atrial natriuretic peptide levels in the prediction of congestive heart failure risk in frail elderly. $\mathscr{F} A M A$ 1992;267:2625-9.

5 Omland T, Aarsland T, Aakvaag A, et al. Prognostic value of plasma atrial natriuretic factor, norepinephrine and epinephrine in acute myocardial infarction. Am $\mathcal{f}$ Cardiol 1993;72:255-9.

6 Lerman A, Gibbons RJ, Rodeheffer RJ, et al. Circulating $\mathrm{N}$-terminal atrial natriuretic peptide as a marker for symptomless left-ventricular dysfunction. Lancet 1993;341: 1105-9.

7 Hall C, Rouleau JL, Moyè L, et al. N-terminal proatrial natriuretic factor. An independent predictor of long-term prognosis after myocardial infarction. Circulation 1994;89: prognosis

8 Hall C, Cannon CP, Forman S, et al. Prognostic value of N-terminal proatrial natriuretic factor plasma levels measured within the first 12 hours after myocardial infarction. $\mathcal{F}$ Am Coll Cardiol 1995;26:1452-6. 
9 Dickstein K, Larsen AI, Bonarjee V, et al. Plasma proatrial natriuretic factor is predictive of clinical status in patients with congestive heart failure. Am f Cardiol 1995;76:67983.

10 Davidson NC, Naas AA, Hanson JK, et al. Comparison of atrial natriuretic peptide, B-type natriuretic peptide, and $\mathrm{N}$-terminal proatrial natriuretic peptide as indicators of left ventricular systolic dysfunction. Am f Cardiol 1996;77 828-31.

11 Yamamoto K, Burnett JC, Jougasaki M, et al. Superiority of brain natriuretic peptide as a hormonal marker of ventricular systolic and diastolic dysfunction and ventricular hypertrophy. Hypertension 1996;28:988-94.

12 Benedict CR, Shelton B, Johnstone DE, et al. Prognostic significance of plasma norepinephrine in patients with asymptomatic left ventricular dysfunction. Circulation 1996;94:690-7.

13 Omland T, Aakvaag A, Bonarjee VVS, et al. Plasma brain natriuretic peptide as an indicator of left ventricular systolic function and long-term survival after acute myocardial infarction. Circulation 1996;93:1963-9.

14 Arakawa N, Nakamura $\mathrm{M}$, Aoki $\mathrm{H}$, et al. Plasma brain natriuretic peptide concentrations predict survival after acute myocardial infarction. $\mathcal{F}$ Am Coll Cardiol 1996;27: $1656-61$

15 Nicklas JM, Benedict C, Johnstone DE, et al. Relationship between neurohumoral profile and one year mortality in patients with CHF and/or LV dysfunction [abstract]. Circulation 1991;84(suppl II):468.

16 Darber D, Davidson NC, Gillespie N, et al. Diagnostic value of B-type natriuretic peptide concentrations in patients with acute myocardial infarction. Am f Cardiol 1996;78: 284-7.

17 Motwani JG, McAlpine H, Kennedy N, et al. Plasma brain natriuretic peptide as an indicator for angiotensinconverting-enzyme inhibition after myocardial infarction. Lancet 1993;341:1109-13.

18 Yandle T, Espiner E, Nicholls M, et al. Radioimmunoassay and characterisation of atrial natriuretic peptide in human plasma. F Clin Endocrinol Metab 1986;61:71-8.
19 Yandle TG, Richards AM, Gilbert A, et al. Assay of brain natriuretic peptide (BNP) in human plasma: evidence for high molecular weight BNP as a major plasma component in heart failure. F Clin Endocrinol Metab 1993;76:832-8

20 Steiner A, Parker C. Kipnis D. Radioimmunoassay for cyclic nucleotides. F Biol Chem 1972;247:1106-13.

21 Goldstein DS, Feurstein G, Izzo JL, et al. Validity and reliability of liquid chromatography with electrochemical detection for measuring plasma levels of norepinephrine and epinephrine in man. Life Sci 1981;28:467-75.

22 Hanley JA, McNeil BJ. The meaning and use of the area under a receiver operating characteristic (ROC) curve. under a receiver operating
Radiology 1982;143:29-36.

23 Anker SD, Coats AJS. Predictors of impaired survival in CHF. Lancet 1996;348:1530-1.

24 Bonow RO. New insights into the cardiac natriuretic peptides. Circulation 1996;93:1946-50.

25 Sussex BA, Arnold JMO, Parker JO, et al. Independent and interactive prognostic information of neurohormones and echocardiogram in high risk post-MI patients [abstract]. 7 Am Coll Cardiol 1992;19:205A.

26 Pacher R, Bergler-Klein J, Globits S, et al. Plasma big endothelin-1 concentrations in congestive heart failure patients with or without systemic hypertension. Am f Cardiol 1993;71:1293-9.

27 Omland T, Lie RT, Aakvaag A, et al. Plasma endothelin determination as a prognostic indicator of 1-year mortality after acute myocardial infarction. Circulation 1994;89: $1573-9$

28 Pacher R, Stanek B, Hülsmann M, et al. Prognostic impact of big endothelin-1 plasma concentrations compared with invasive hemodynamic evaluation in severe heart failure. $f$ Am Coll Cardiol 1996;27:633-41.

29 Habib FM, Springall DR, Davies GJ, et al. Tumour necrosis factor and inducible nitric oxide synthase in dilated cardiomyopathy. Lancet 1996;347:1151-5.

30 Levine B, Kalman J, Mayer L, et al. Elevated circulating levels of tumor necrosis factor in severe chronic heart failure. N Engl F Med 1990;323:236-41. 